\title{
Clinimetric evaluation of active range of motion measures in patients with non-specific neck pain: a systematic review
}

\author{
Chantal H. P. de Koning · Sylvia P. van den Heuvel • \\ J. Bart Staal · Bouwien C. M. Smits-Engelsman · \\ Erik J. M. Hendriks
}

Received: 12 November 2007/Revised: 11 February 2008/Accepted: 9 March 2008/Published online: 22 April 2008

(C) The Author(s) 2008

\begin{abstract}
The study is to provide a critical analysis of the research literature on clinimetric properties of instruments that can be used in daily practice to measure active cervical range of motion (ACROM) in patients with non-specific neck pain. A computerized literature search was performed in Medline, Cinahl and Embase from 1982 to January 2007. Two reviewers independently assessed the clinimetric properties of identified instruments using a criteria list. The search identified a total of 33 studies, investigating three different types of measurement instruments to determine ACROM. These instruments were: (1) different types of goniometers/inclinometers, (2) visual estimation, and (3) tape measurements. Intra- and inter-observer reliability was demonstrated for the cervical range of motion instrument (CROM), Cybex electronic digital instrument (EDI-320) and a single inclinometer. The presence of agreement was assessed for the EDI-320 and a single inclinometer. The CROM received a positive rating for construct validity. When clinical acceptability is taken into
\end{abstract}

C. H. P. de Koning $(\bowtie)$ • B. C. M. Smits-Engelsman

Avans+, University for Professionals, Breda,

The Netherlands

e-mail: cdekoning@zeelandnet.nl

S. P. van den Heuvel · E. J. M. Hendriks

Dutch Institute for Allied Health Care (NPi),

Amersfoort, The Netherlands

J. B. Staal · E. J. M. Hendriks

Department of Epidemiology, Centre for Evidence Based

Physiotherapy and Caphri Research Institute, Maastricht

University, Maastricht, The Netherlands

B. C. M. Smits-Engelsman

Motor Control Lab, Department of Kinesiology,

K.U. Leuven, Leuven, Belgium account both the CROM and the single inclinometer can be considered appropriate instruments for measuring the active range of motion in patients with non-specific neck pain in daily practice. Reliability is the aspect most frequently evaluated. Agreement, validity and responsiveness are documented less frequently.

Keywords Non-specific neck pain .

Active range of motion - Reproducibility of results .

Systematic review

\section{Introduction}

Neck pain is a common musculoskeletal disorder. The incidence of neck pain in the Netherlands has been estimated as 23.1 per 1,000 person years [12]. In general, women have more neck pain than men $[12,27]$. In the Netherlands, $51 \%$ of patients with acute non-specific neck pain who consulted their general practitioners were referred to physiotherapists for treatment [79].

Neck pain may result from many causes (trauma, infections or inflammatory conditions, rheumatic disorders and congenital diseases), but most often no specific cause can be found and the condition is labelled as non-specific neck pain [10]. In their clinical examination, physiotherapists and other healthcare providers may routinely perform an assessment of the active cervical range of motion (ACROM) to assess the level of impairment associated with neck pain as well as the results of treatment. Typical ACROM assessments of the cervical spine include flexion and extension in the sagittal plane, lateral flexion in the frontal plane and rotation in the transverse plane. Tests or instruments which are used to examine ACROM in patients with non-specific neck pain should meet several clinimetric 
prerequisites, such as an acceptable level of reproducibility, validity and responsiveness [29].

Recently, several systematic reviews have been published on the assessment of passive cervical range of motion (PCROM) and palpation procedures of the cervical spine $[62,64,75]$. Among the palpation procedures, pain provocation tests were found to be the most reliable [62, 64] and the assessment of regional PCROM was found to be more reliable than segmental PCROM [62]. However, in these reviews it was also concluded that most studies were of a poor methodological quality $[62,64,75]$.

In 2000, a review was published that assessed the reliability of tools used to measure ACROM. This review concluded that the cervical range of motion device has shown promising reliability [38]. Our overview takes account not only of reliability, but also of validity and responsiveness.

The objective of the present systematic review, therefore, is to provide an overview of the current knowledge on clinimetric properties of instruments that are practical to use when evaluating ACROM in patients with non-specific neck pain.

\section{Methods}

\section{Study selection}

An extensive search was conducted in the MEDLINE (1982 to January 2007), CINAHL (1982 to January 2007) and EMBASE (1996 to January 2007) databases. The following search terms were used: neck, cervical, reproducibility of results, reliability, reproducibility, validation studies, validity, responsiveness, range of motion, active motion, movement. In addition, after the selection of relevant studies, the specific names of identified assessment instruments were used for an additional computerized search to identify supplementary relevant studies. References from retrieved papers were searched for additional studies. The principle investigator (CK) screened the potentially relevant papers retrieved for eligibility according to the following inclusion criteria:

The paper had to be written in English or Dutch;

Studies had to pertain to the cervical or upper thoracic spine;

Studies had to investigate the reproducibility, validity or responsiveness of instruments or tests for measuring ACROM;

The instrument or test used had to be described clearly, enabling eventual replication of the test,

And the instrument or test had to be portable, affordable (maximum 1,000 Euros) and easy to use (time to test maximum $5 \mathrm{~min}$ ) by healthcare professionals in daily practice.

Studies were excluded if they were non-published papers (thesis studies).

Data abstraction and quality assessment

We investigated the following clinimetric properties: intraobserver reliability, interobserver reliability, agreement, construct validity, responsiveness and interpretability. To interpret the data a checklist was composed that was partly based on criteria developed by the Scientific Advisory Committee of the Medical Outcome Trust [46] and a checklist developed by Bot et al. [11] (Table 1).

Description of the instruments for the assessment of ACROM

Descriptive data extracted from the publications included the target population and the examiners, description of test/ instrument and protocol used, description of test-retest interval, blinding of examiners for participants and each other's or reference test result, and explanation of withdrawals.

Reproducibility

Reproducibility is the extent to which an instrument yields stable scores over time among respondents who are assumed not to have changed [67]. Reproducibility was assessed by rating reliability and agreement. Reliability represents the extent to which individuals can be distinguished from each other, despite measurement errors. Agreement represents a lack of measurement error [67].

The weighted kappa was considered adequate for calculating the reliability of ordinal data, and calculation of the intra-class correlation coefficient (ICC) was considered an adequate measure for ordinal or parametric data [31]. Intraobserver reliability and interobserver reliability were rated positive if the ICC was $>0.85$ and $>0.70$ respectively $[29,66]$. A kappa coefficient above 0.60 was rated positively for intra- and inter-observer reliability. This is based on the Landis and Koch scale [43] 0.41-0.60 moderate correlation, 0.61-0.80 substantial correlation and 0.811.00 almost perfect correlation. Application of the Pearson reliability coefficient was rated as doubtful, as it neglects systematic observer bias [31].

Agreement is the ability to achieve the same value with repeated measurements. For this review, calculations of the $95 \%$ limits of agreement (LoA), standard error of measurement (SEM), smallest detectable change (SDC) or 
Table 1 Checklist used for the assessment of clinimetric properties of the studies included

\begin{tabular}{|c|c|c|}
\hline Clinimetric property & Definition & Criteria \\
\hline Reproducibility & $\begin{array}{l}\text { Degree to which repeated } \\
\text { measurements in stable persons } \\
\text { provide similar answers }\end{array}$ & $\begin{array}{l}\text { K: nominal/ordinal data } \\
\text { ICC: ordinal/parametric data } \\
+ \text { Adequate design, method, intraobserver }\end{array}$ \\
\hline Reliability & $\begin{array}{l}\text { The extent to which patients can be } \\
\text { distinguished from each other, } \\
\text { despite measurement error }\end{array}$ & $\begin{array}{l}\text { ICC }>0.85 \text { or } K>0.41 \text { interobserver ICC }>0.70 \\
\text { or } K>0.41 \\
\pm \text { Adequate design, method, intraobserver }\end{array}$ \\
\hline Agreement & $\begin{array}{l}\text { The ability to achieve the same } \\
\text { value with repeated measurements }\end{array}$ & $\begin{array}{l}\text { ICC }<0.85 \text { or } K<0.40 \text { interobserver ICC }<0.70 \\
\text { or } K<0.40 \\
\text { ? Doubtful method used } \\
\text { o No information found } \\
\text { Limits of agreement, SEM or SDC are presented } \\
+ \text { Adequate design method and result } \\
\text { ? Doubtful method used } \\
\text { - No information found }\end{array}$ \\
\hline Construct validity & $\begin{array}{l}\text { The extent to which a test identifies } \\
\text { the concept or trait of which is } \\
\text { being measured }\end{array}$ & $\begin{array}{l}\text { Pearson R or Spearman Rho } \\
+ \text { Adequate design, method, } r>0.65 \\
\text { ? Doubtful method used } \\
\text { - Inadequate construct validity } \\
\text { o No information found }\end{array}$ \\
\hline Responsiveness & $\begin{array}{l}\text { Ability of an instrument to detect } \\
\text { important change over time in the } \\
\text { concept being measured }\end{array}$ & $\begin{array}{l}\text { Hypotheses were formulated and results are in } \\
\text { agreement } \\
+ \text { Adequate design method and result } \\
\text { ? Doubtful method used } \\
\text { - Inadequate responsiveness } \\
\text { o No information found }\end{array}$ \\
\hline Interpretability & $\begin{array}{l}\text { The degree to which one can assign } \\
\text { qualitative meaning to } \\
\text { quantitative scores }\end{array}$ & $\begin{array}{l}\text { Authors provided information on the interpretation } \\
\text { of scores, MIC defined Mean and SD scores } \\
\text { before and after treatment }\end{array}$ \\
\hline
\end{tabular}

$K$ Kappa statistics, $I C C$ intraclass correlation coefficient, SEM standard error of measurement, $S D C$ smallest detectable change, $M I C$ minimal important change, $S D$ standard deviation

minimal detectable change (MDC) were considered sufficient. The SDC or MDC reflect the smallest withinperson change in score that can be interpreted as a real change, above measurement error $[11,67]$. It is not possible to define adequate cut-off points for the result of an agreement study. For that reason, a positive rating was given when an adequate method for agreement was used.

\section{Validity}

Validity is the degree to which an instrument measures what it is supposed to measure. Construct validity is the extent to which scores on a particular instrument relate to other measures in a manner that is consistent with theoretically derived hypotheses concerning the concept being measured [67]. A Pearson's correlation coefficient or Spearman correlation coefficient above 0.65 was rated positively for construct validity [29, 66].

\section{Responsiveness}

Responsiveness refers to the ability of an instrument to detect important change over time in the concept being measured and is therefore considered to be a measure of longitudinal validity. There is no single agreed method of assessing or expressing an instrument's responsiveness [29, 67]. Responsiveness is considered to have been studied adequately if hypotheses have been specified and the results corresponded to these hypotheses [11]. It was not possible to define adequate cut-off points for the result of a responsiveness study. For that reason, a positive rating was given when an adequate method for responsiveness was used.

\section{Interpretability}

Interpretability is defined as the degree to which scores and change scores can be interpreted and qualitative meaning 
can be assigned to quantitative scores. The investigators should provide information about what difference in score would be clinically meaningful. We rated this on the basis of whether the authors had presented a minimal important change (MIC) or if information was presented that could aid in interpreting scores-for instance, presentation of means and standard deviations (SD) of patient scores before and after treatment, data on distribution of scores in relevant subgroups and relating changes in the instrument score to patients' global perceived change [11, 67].

Overall quality

To obtain an overall score for the quality of the instruments, the number of positive ratings on the abovementioned points was summed for each instrument.

Two investigators (C.K. \& S.H.) independently assessed the studies included according to the criteria list. Disagreements between the reviewers were resolved by discussion. If disagreement persisted about the assignment of a score to an item, a third person (E.H.) was consulted to decide on the final rating.

\section{Results}

Selection of the studies

The search generated 549 hits. After screening titles and abstracts, 481 studies were excluded. Of the remaining 68 studies, 33 publications were included after reading the full article $[1-3,8,15,16,20,32-37,41,48,51,53-56,59,61$, 68-71, 73, 77, 78, 80, 84-86].

Reasons for exclusion were the cost of the instruments used $(n=24)$, (these instruments were mainly tested in university laboratories and we estimated that the instruments cost more than 1,000 Euros) $[4,5,7,14,17,19,22-$ $24,28,39,40,42,44,45,49,50,52,57,58,63,65,81,83]$; no clinimetric evaluation of the instrument $(n=9)[6,9,18$, 24, 25, 30, 60, 72, 82], and only assessment of PCROM [47].

The instruments that were included based on the criteria of clinical acceptability were: goniometers/inclinometers (30 articles); visual estimation (two articles) and tape measurements (four articles). Relevant data on study population, examiners, study protocol and results from these studies are displayed in Tables 2, 3 and 4. Initially, there was 94\% agreement on the items that were rated. All disagreements between the two reviewers were solved with discussion.

\section{Goniometers/inclinometers}

Goniometers are versatile devices that measure range of motion in grades and depend on landmarks. Inclinometers are fluid-filled goniometric instruments that depend on gravity. In the literature we included, the terms goniometer and inclinometer are used interchangeably. The instruments included are: variations of universal goniometers [20, 41, 48, 56, 73, 86], a Myrin goniometer [8, 78], a Spin$\mathrm{T}$ goniometer $[1,2,32]$, the cervical range of motion instrument (CROM) [16, 33, 54, 55, 61, 69-71, 84, 85], single inclinometers $[15,20,33,59,80]$, an electronic digital inclinometer EDI-320 [35, 68], a simple inclinometer [51], a gravity action inclinometer [37], a liquid inclinometer [3] and a spirit inclinometer [53] (Fig. 1).

Information on reliability was found for all instruments. In general, the ICC was reported except for most articles published before 1995. The reliability for the CROM, a single inclinometer, and the EDI-320 were rated positively (ICC intraobserver $>0.85$, ICC interobserver $>0.70$ ).

Information on agreement was found for the CROM [54], a universal goniometer [20], spin-T goniometer [32], a single inclometer [20, 59, 80] and the EDI-320 [35].

The EDI-320 (LoA intraobserver $\mathrm{F} / \mathrm{E}-2.5 \pm 11.1^{\circ}$ LFL $-0.1 \pm 10.4^{\circ}$ ROT $-5.9 \pm 13.5^{\circ}$; LoA interobserver F/E $3.3 \pm 17^{\circ}$, LFL $0.5 \pm 17^{\circ}$, ROT $-1.3 \pm 24.6^{\circ}$ ) and a single inclinometer (SEM ranged from $3.6^{\circ}$ to $7^{\circ}$ and MDC ranged from $10^{\circ}$ to $19^{\circ}$ ) were rated positively (Fig. 2).

Construct validity of the CROM was determined by comparing CROM with radiographics, a single inclinometer and opto-electronic systems [33, 55, 69-71]. The Spin$\mathrm{T}$ goniometer was compared with motion star equipment [2]. The rangiometer and universal goniometer were compared with each other [86] and with the age and disease duration of patients with ankylosing spondylitis [48]. A single inclinometer was compared with results on the neck disability index (NDI) [59] and radiographics [15].

Construct validity of the spin-T goniometer, universal goniometer, rangiometer and single inclinometer were rated as doubtful, because different statistics were used as the predefined criterion for the Pearson correlation coefficient $(r)$ or $r<0.65$. The CROM gets a positive rating; $r>0.65$.

Information on responsiveness was only found for the universal goniometer, measured on patients with ankylosing spondylitis [48] and therefore gets a doubtful rating for the present patient group.

Visual estimation

When performing a visual estimation the patient sits and the examiner visually estimates the ACROM. Two articles described the interobserver reliability of visual estimation $[34,77]$. Both articles presented Kappa values that were below the predefined criteria and therefore the reliability of visual estimation was rated as inadequate. Information on agreement, validity and responsiveness was not found. 


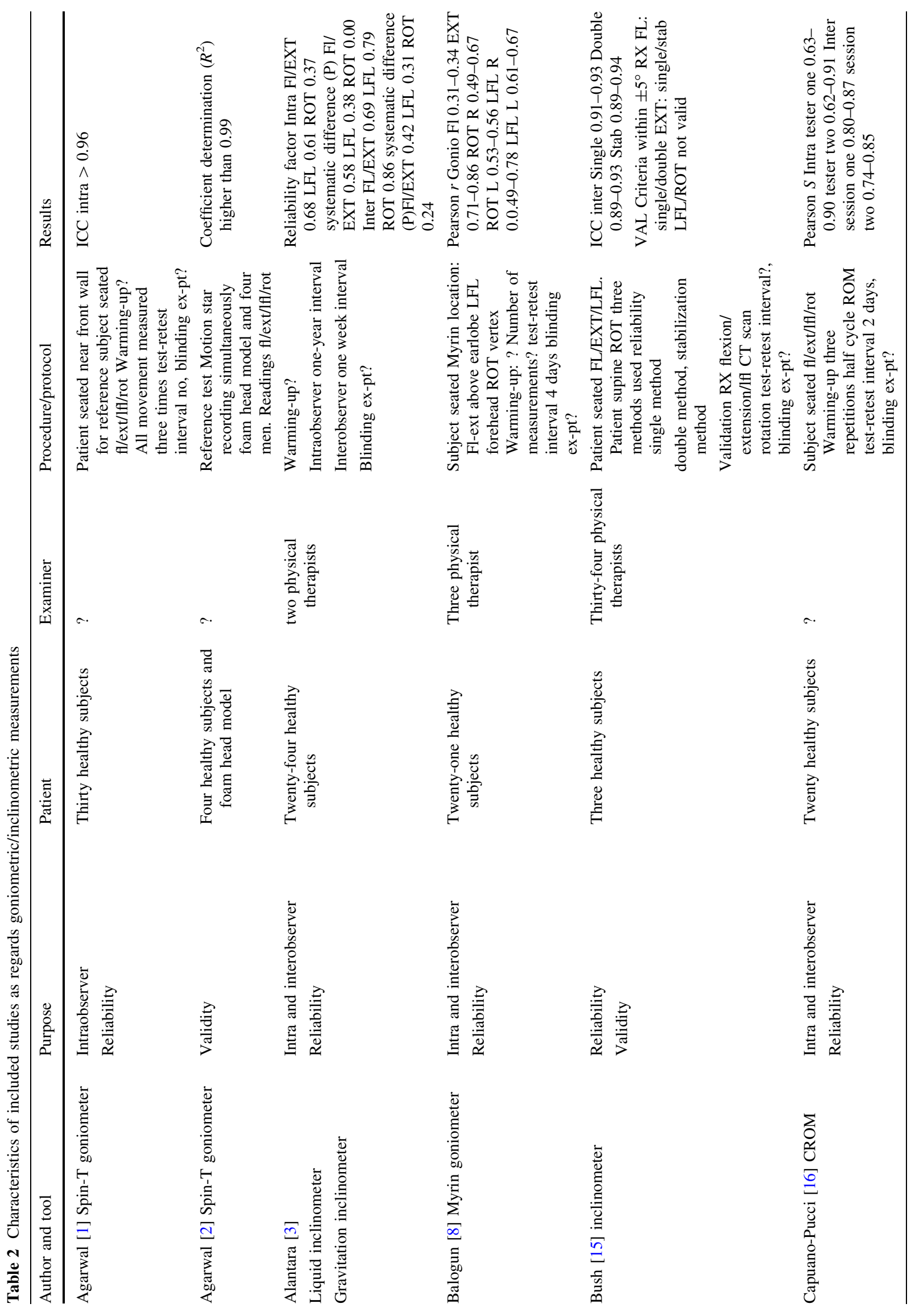




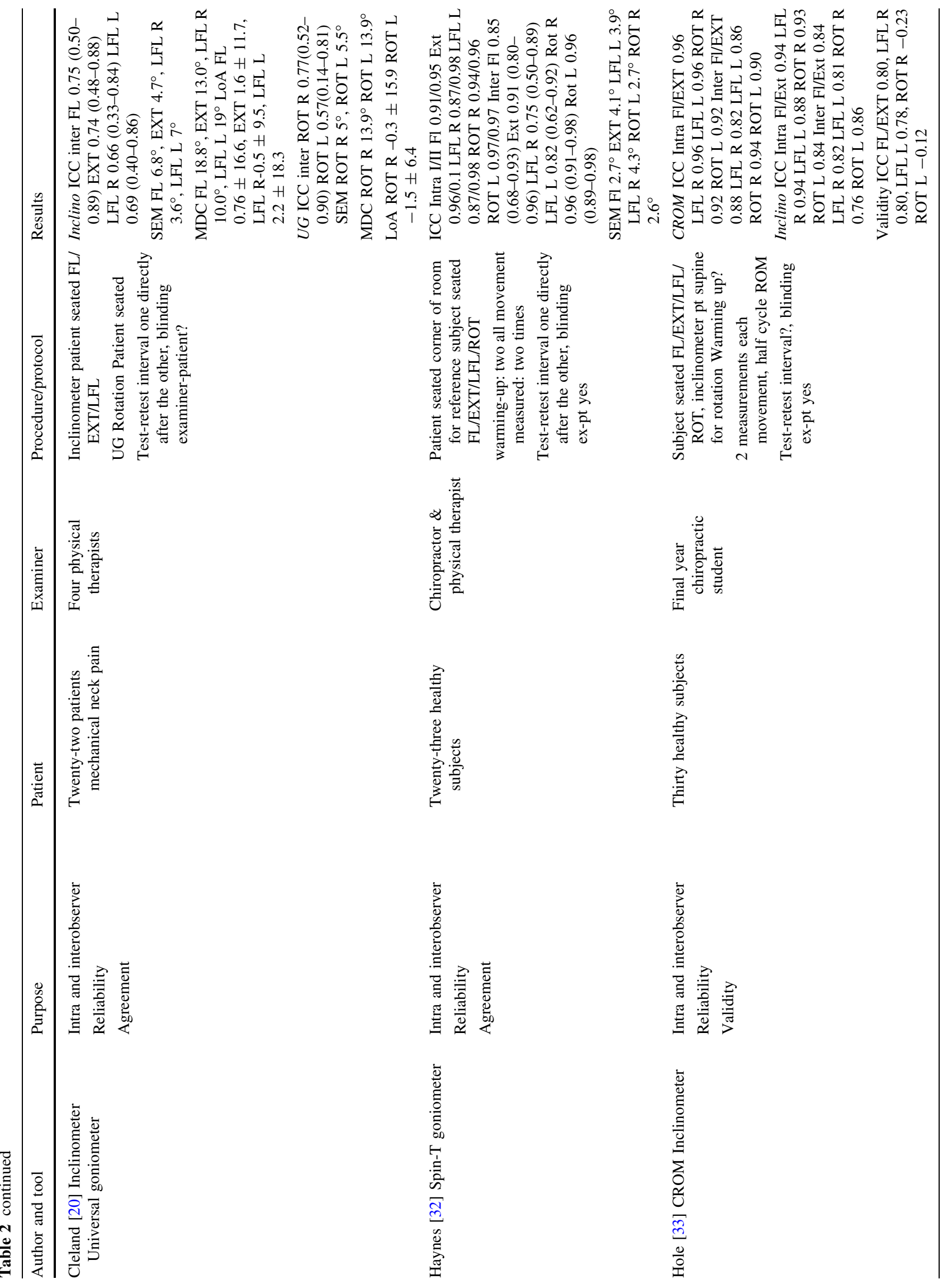




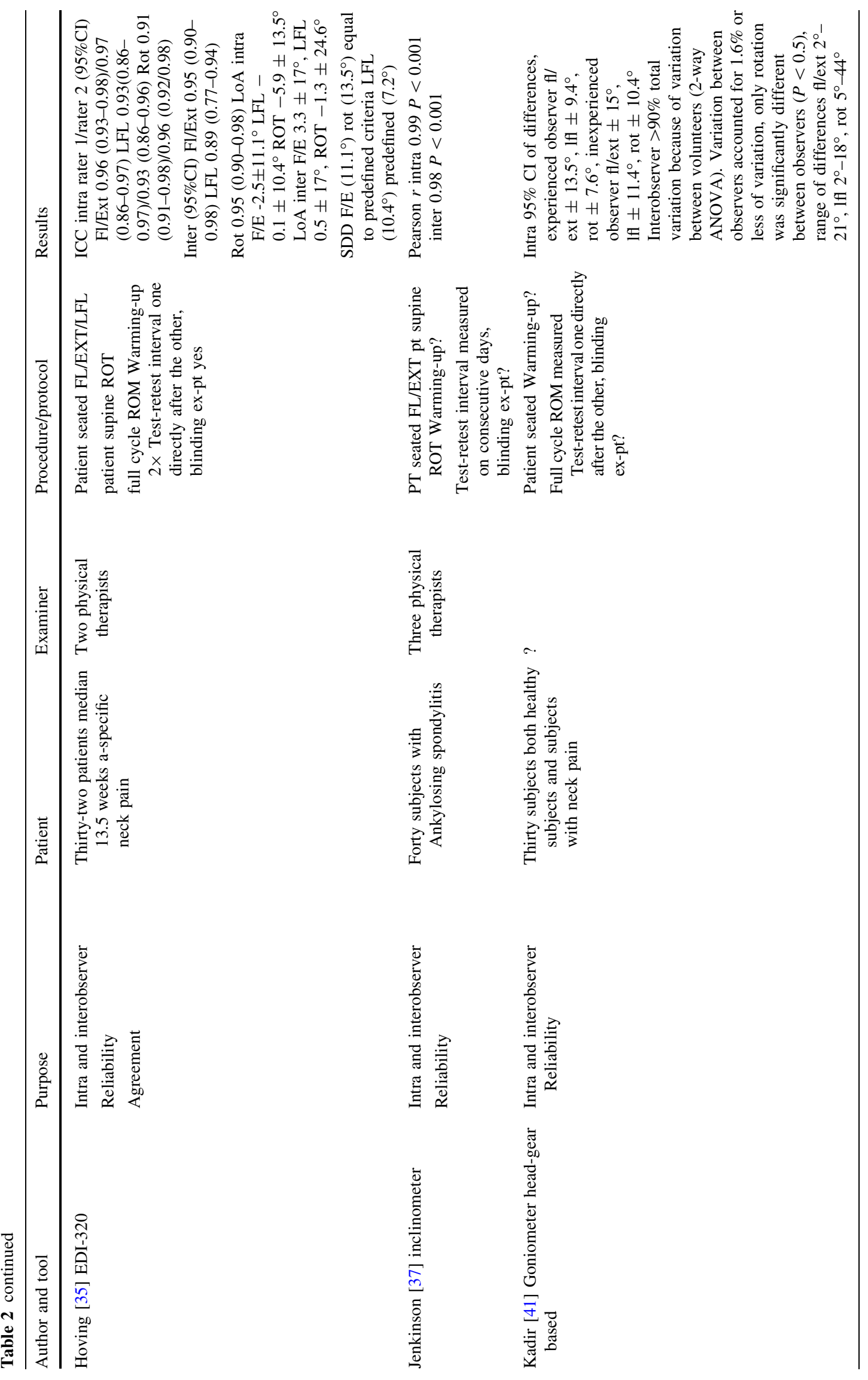




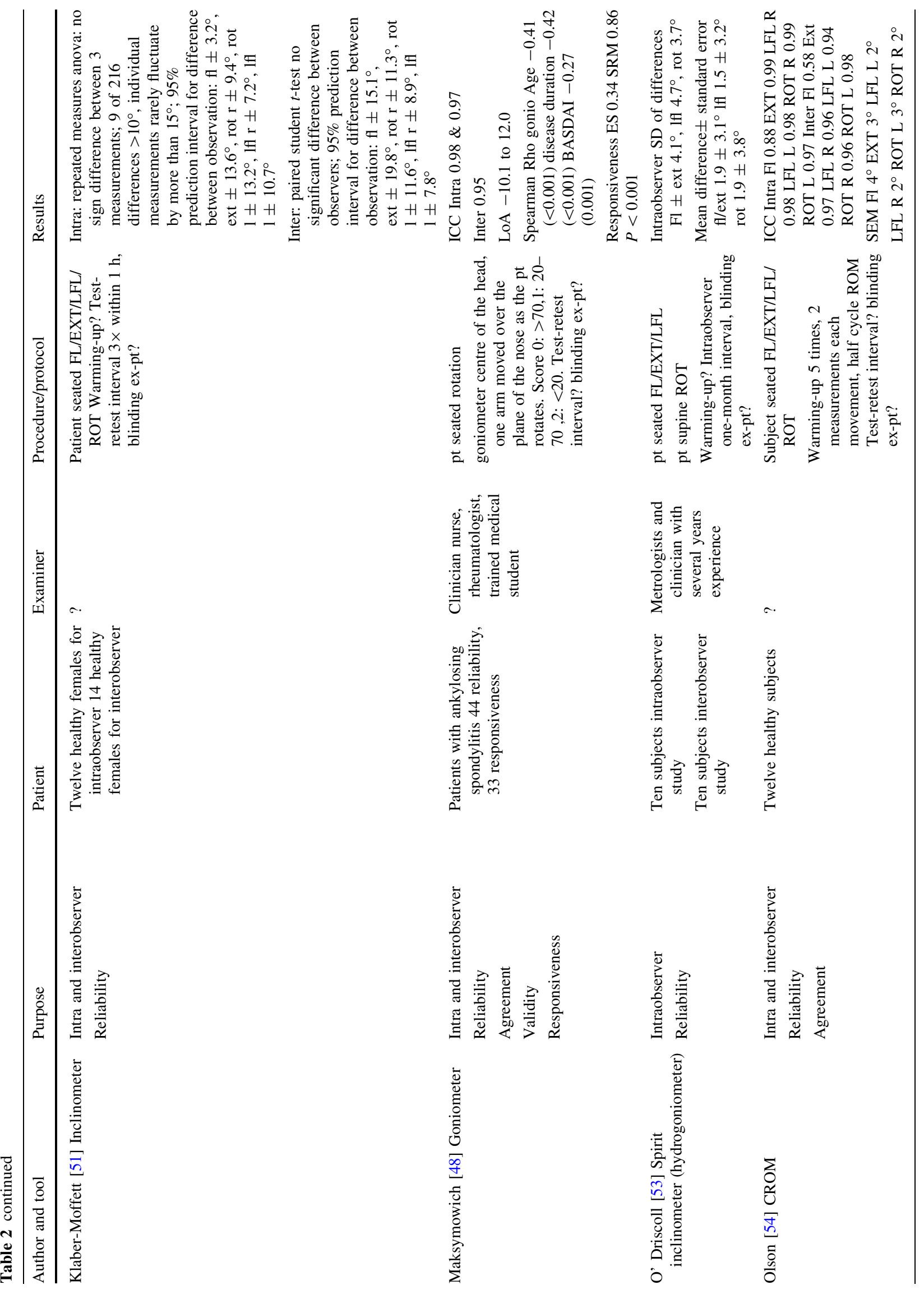




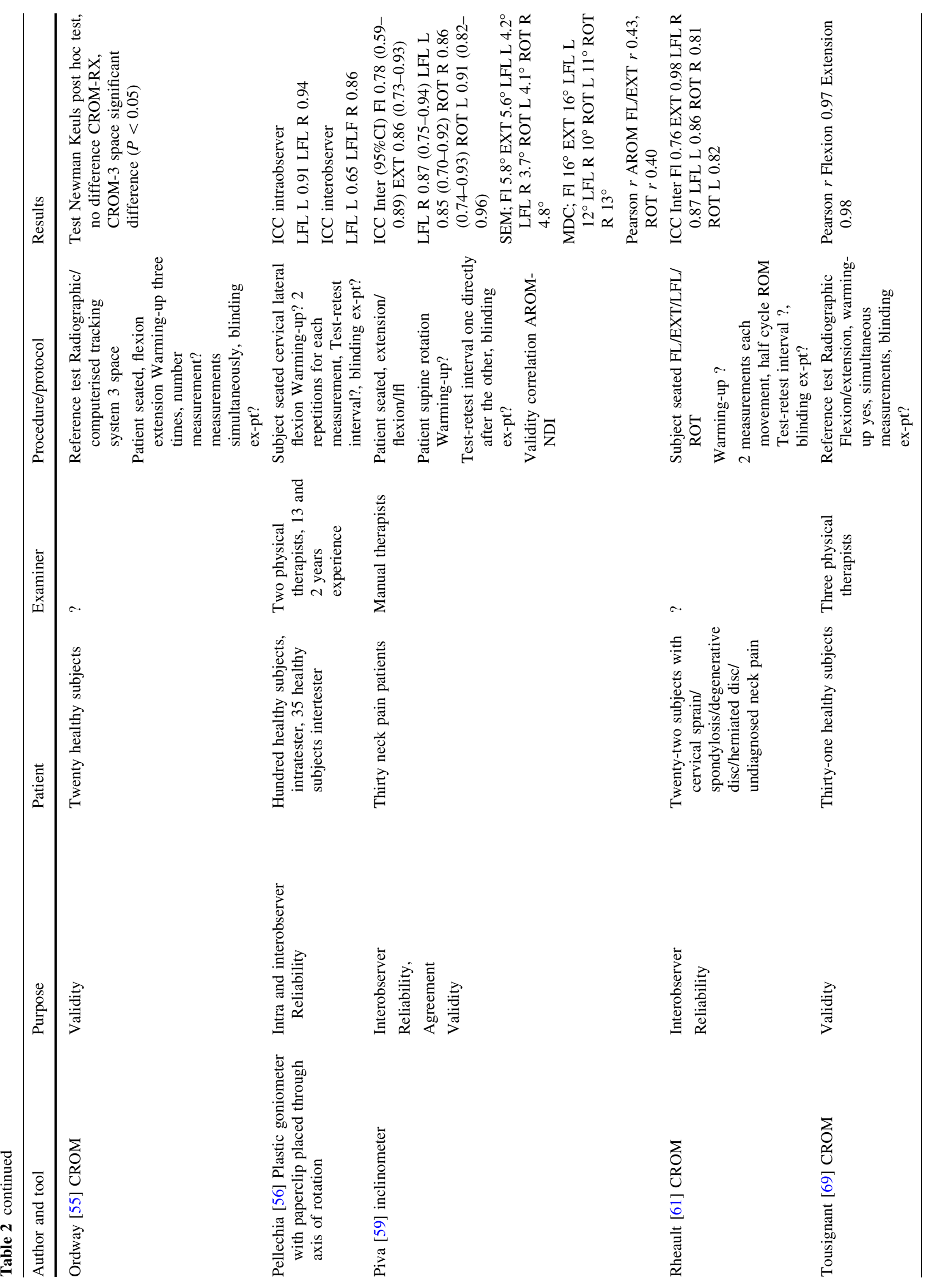




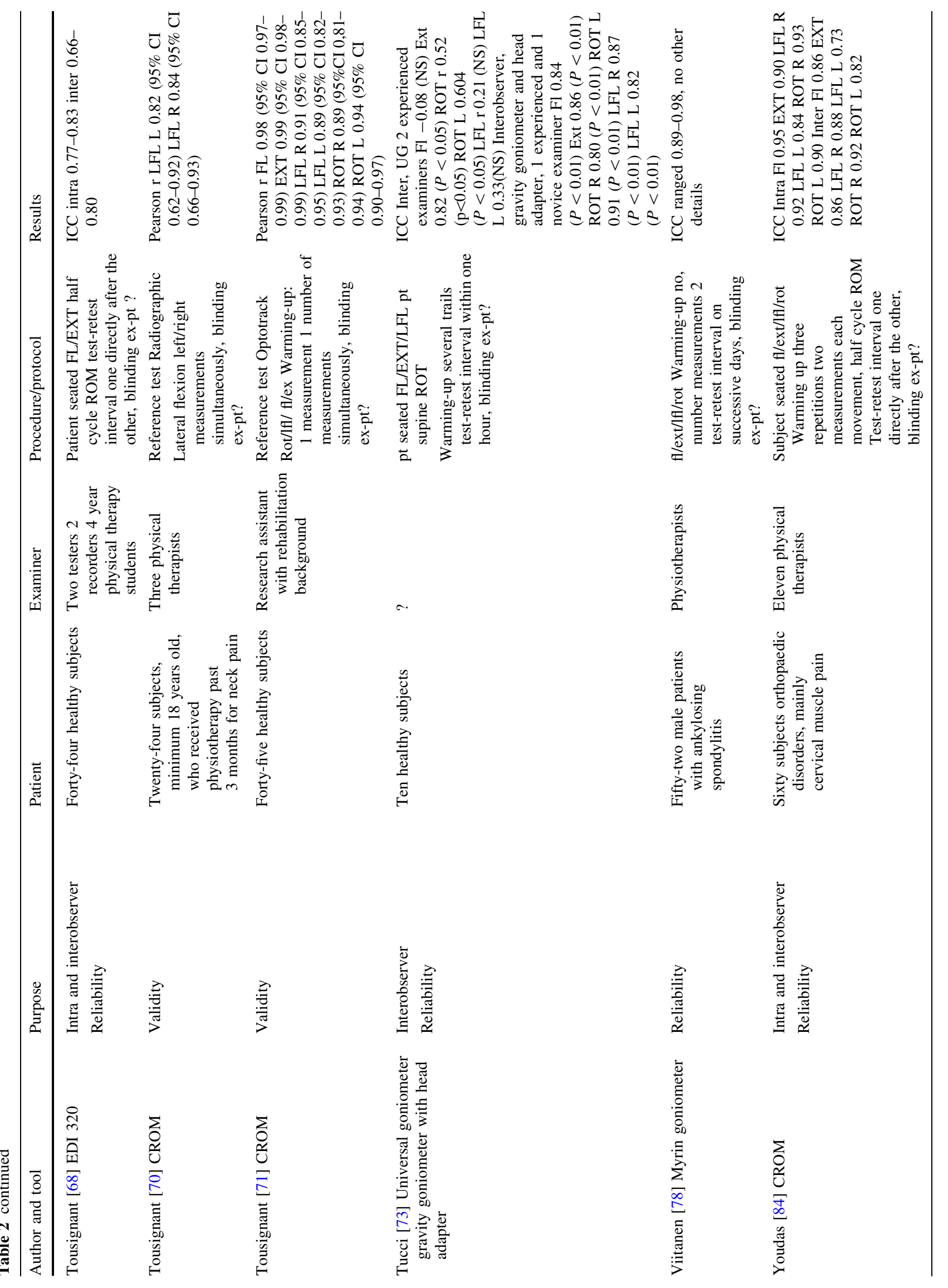




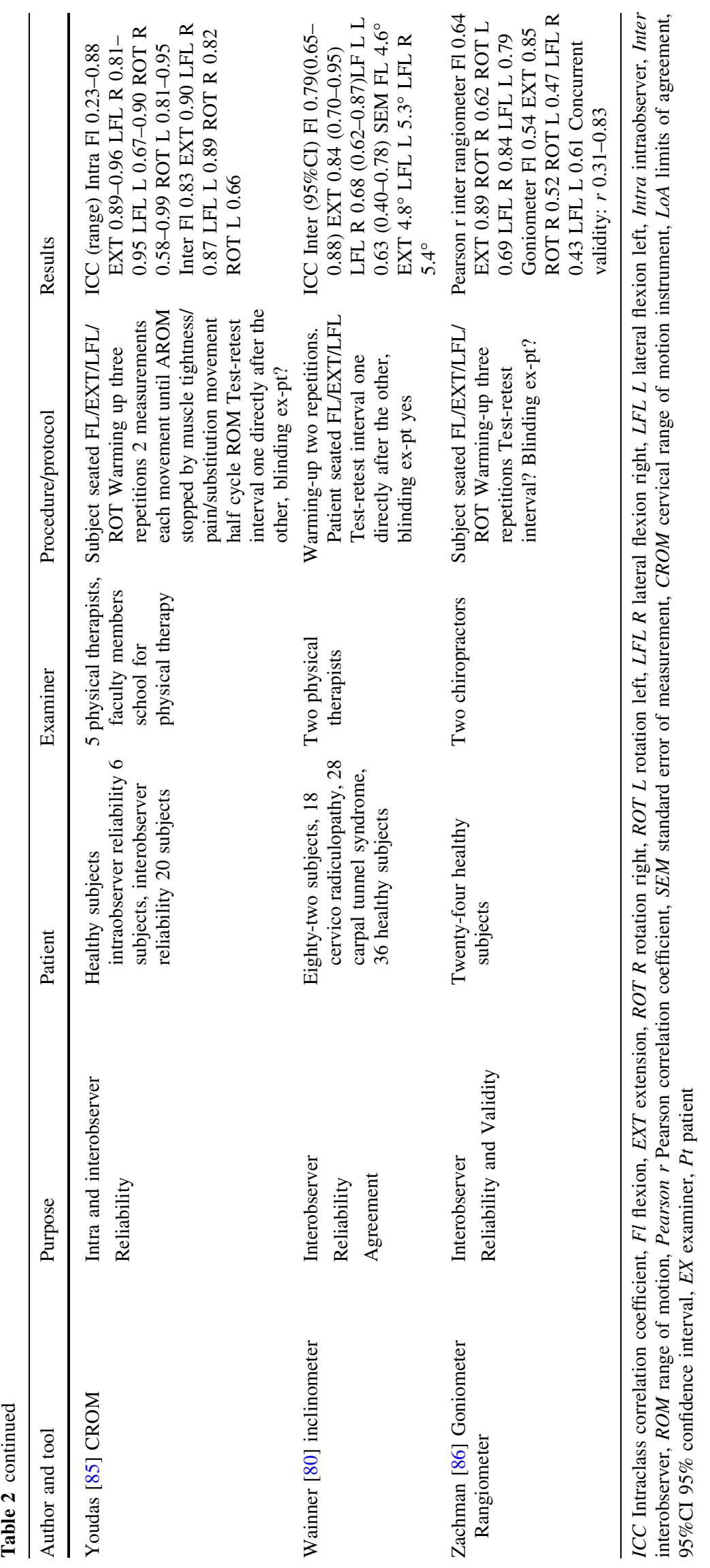


Table 3 Characteristics of included studies as regards visual estimation

\begin{tabular}{|c|c|c|c|c|c|}
\hline Author and tool & Purpose & Patient & Examiner & Procedure/protocol & Results \\
\hline $\begin{array}{l}\text { Hoppenbrouwers } \\
\text { [34] Visual } \\
\text { estimation }\end{array}$ & $\begin{array}{r}\text { Interobserver } \\
\text { Reliability }\end{array}$ & $\begin{array}{l}\text { Sixty-nine } \\
\text { subjects, } \\
\text { healthy and } \\
\text { non-specific } \\
\text { neck pain }\end{array}$ & $\begin{array}{l}\text { Twenty-four-year } \\
\text { physiotherapy } \\
\text { students }\end{array}$ & $\begin{array}{l}\text { Active ROM, as described by Dos } \\
\text { Winkel, warming up one repetition, } \\
1 \text { measurement classification } \\
\text { restricted or not test-retest interval? } \\
\text { blinding ex-pt yes }\end{array}$ & $\begin{array}{l}\text { K inter Fl 0.57 Ext 0.88 ROT (1/ } \\
\text { r) } 0.49 \text { (L: } 0.43 / \mathrm{R}: 0.54) \text { LFL } \\
\text { (1/r) } 0.35 \text { (L: } 0.33 / \mathrm{R}: 0.36) \text { All } \\
\text { movements Together } 0.52\end{array}$ \\
\hline $\begin{array}{l}\text { Viikari-Juntura } \\
\text { [77] Visual } \\
\text { estimation }\end{array}$ & $\begin{array}{r}\text { Interobserver } \\
\text { Reliability }\end{array}$ & $\begin{array}{l}\text { Fifty-two } \\
\text { patients } \\
\text { neck and } \\
\text { radicular } \\
\text { pain }\end{array}$ & $\begin{array}{l}\text { Physician in } \\
\text { physical } \\
\text { medicine and } \\
\text { rehabilitation } \\
\text { and physical } \\
\text { therapist }\end{array}$ & $\begin{array}{l}\text { Warming-up active ROM Fl/ext } \\
\text { normal }>45^{\circ} \text { limited } 30-45^{\circ} \\
\text { markedly limited }<30^{\circ} \text { ROT normal } \\
>80^{\circ} \text { limited } 60-80^{\circ} \text { markedly } \\
\text { limited }<60^{\circ} \text { LFL normal }>30^{\circ} \\
\text { limited } 20^{\circ}-30^{\circ} \text { markedly limited } \\
<20^{\circ} \text { test-retest interval } 1 \mathrm{~h}, \\
\text { blinding ex-pt yes }\end{array}$ & $\begin{array}{l}\text { Kw inter Fl } 0.43 \text { Ext } 0.56 \text { ROT } \\
\text { R 0.56 ROT L } 0.40 \text { LFL R } \\
0.51 \text { LFL L } 0.41\end{array}$ \\
\hline
\end{tabular}

$R O M$ Range of motion, $F L$ flexion, EXT extension, ROT rotation, $L F L$ lateral flexion, $K$ Kappa statistics, $K w$ weighted Kappa

Tape measurement

Neck mobility was measured with tape in centimetres with different landmarks as reference marks. Different measurement protocols were found. Two studies described the Pearson correlation coefficient $[8,36]$ as a statistic measure for intra- and inter-observer reliability. Information on reliability, described by the ICC, agreement and responsiveness were found for patients with ankylosing spondylitis [48, 78]. Tape measurement was rated as doubtful for reproducibility and responsiveness.

Overall quality

The rating of the clinimetric qualities of the instruments included is presented in Table 5, summarizing each aspect as positive, inadequate, doubtful or insufficient quality. Only a few studies gave an adequate description of the study design and population characteristics. Eight studies included only patients with non-specific neck pain; twenty publications provided insufficient information on the methodological aspects to enable a good appraisal of the study design. Furthermore, information about non-response and subjects' loss to follow-up was often lacking.

\section{Discussion}

An extensive search strategy led to the identification of three different types of instruments for the evaluation of active cervical ROM which are easily applicable in daily clinical practice and for which clinimetric properties have been investigated. Overall, the CROM, a single inclinometer and EDI-320 had the best ratings on such clinimetric aspects as reproducibility, validity and responsiveness. When clinical acceptability is taken into account the CROM or a single inclinometer can be considered to be the most appropriate instruments for the assessment of ACROM in patients with non-specific neck pain. In other patients groups, as for example in patients with cervical disc prostheses the CROM can possibly be used to measure follow-up of range of motion. The authors believe that the CROM may be a cheap and safe alternative instrument instead of radiography. Radiography then only has to be used in those patients in which ACROM does not improve as was expected.

The CROM had been studied most extensively. None of the instruments received positive ratings for all items of the methodological quality checklist. It has been advocated that agreement parameters are required for instruments that are used for evaluative purposes and reliability parameters are required for instruments that are used for discriminative purposes [21]. Instruments used to measure ACROM are mainly used for evaluative purposes, but reliability parameters have been studied more extensively than agreement parameters. Agreement, interpretability and responsiveness are clinimetric properties, which in general have not been tested. For evaluative purposes, these clinimetric properties are important because measurement error should be smaller than the minimal change that is considered to be important [67]. Parameters were only found for the single inclinometer and the EDI-320 agreement in studies that have an adequate study design. MDC values of a single inclinometer ranged from $10^{\circ}$ (lateral flexion) to $16^{\circ}$ (flexion/extension) [20, 59, 80].

The methodological quality of the studies included varied. In total we included 33 publications. In general, the methodological quality of the older literature (published before 1995) is lower than the more recent literature. Older articles mainly describe reliability and eight of those articles did not use the ICC as a statistical measurement for reliability [3, 8, 16, 36, 37, 41, 51, 86].

In order to ensure external validity it is necessary to include patients with neck pain who are likely to undergo 


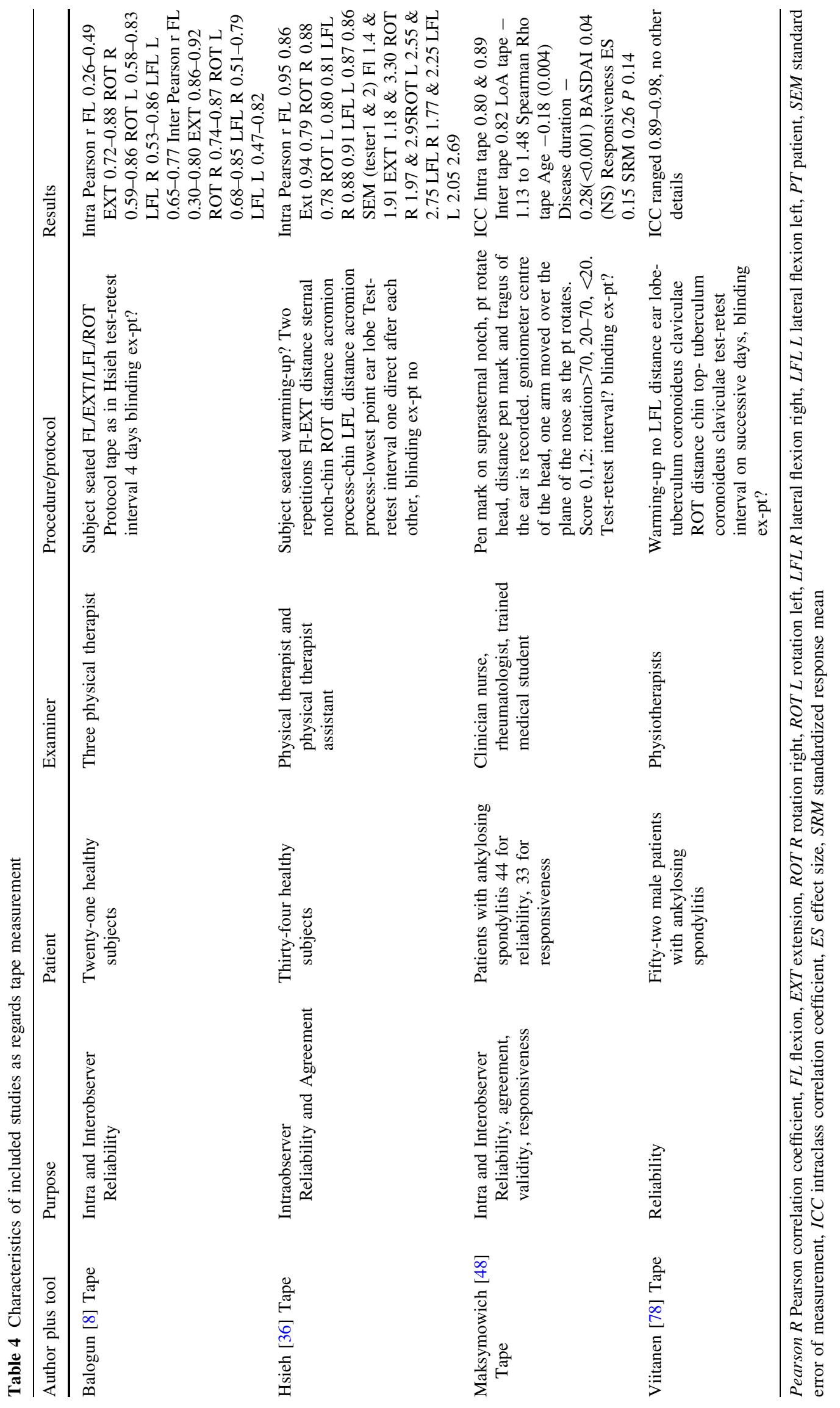




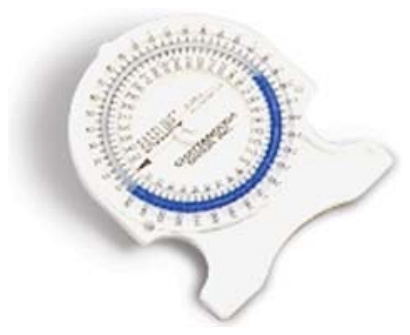

Fig. 1 Inclinometer

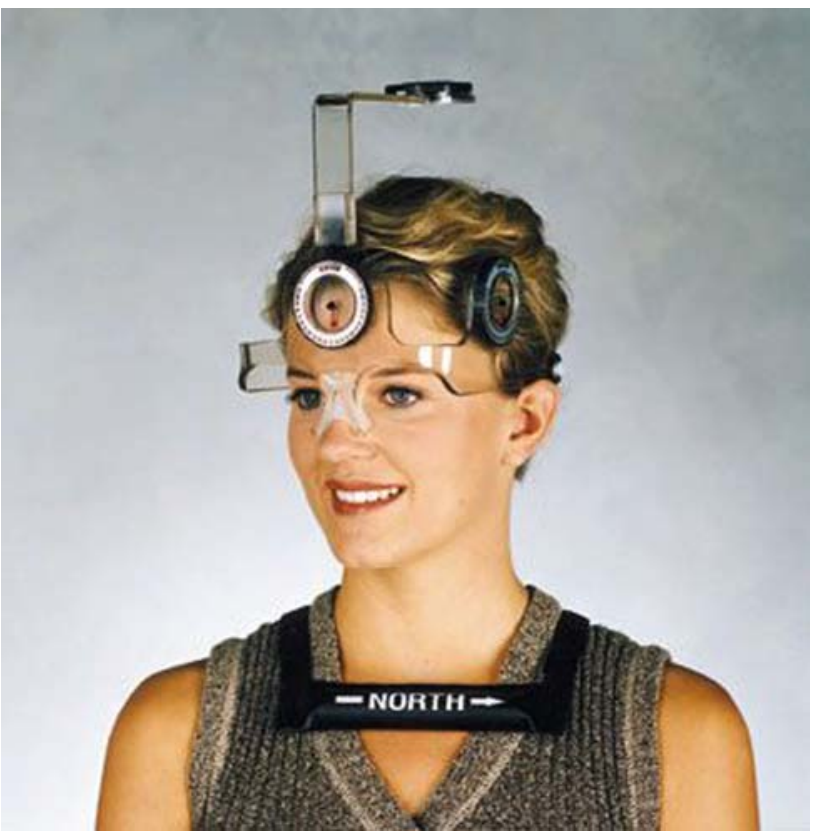

Fig. 2 Cervical range of motion instrument

the same measurement procedure in daily practice [13]. Nineteen articles used healthy subjects $[2,3,8,15,16,32$, $33,36,51,53-56,68,69,71,73,85,86], 4$ articles used patients other than non-specific neck pain patients [37, 48, $78,80]$ and 9 articles included patients with non-specific neck pain $[20,34,35,41,59,61,70,77,84]$.

Thirteen publications did not describe the training and the results of the training undergone by those doing the rating prior to the test, which is however an important aspect of external validity [74]. Blinding is an important aspect of the internal validity of a study. It can be divided into examiner-participant blinding and examiner-examiner blinding. Blinding of examiner-participant is often not described in the publications included in this review. The aspect of blinding examiner-examiner is given more consideration in the publications.

This review has several limitations. Although much effort was made to find all the published studies, selection bias may have occurred because only Dutch or Englishlanguage articles were included. Effort was put into reference tracking but it is possible that studies were missed. Furthermore, unpublished studies were not included. Reviewer bias is also a possible limitation of this review because reviewers were not blinded to the authors.

There is no gold standard for evaluating clinimetric qualities. The checklist used in our review was based on the checklist made by Bot et al. [11]. This list has been used previously for patient-assessed questionnaires instead of instruments to evaluate the functional status of the patient $[11,26,76]$. This checklist, however, was chosen for its quality and international consensus on terminology. Assigning value labels for ranges of Kappa and ICC statistics and correlation coefficients was done in accordance with other authors [29, 43, 66, 67].

Jordan [38] concluded in his review that the CROM has shown promise as regards reliability but its practicality for clinical use is questionable because of the costs involved and its dimensions. The author also concluded that evidence on the single inclinometer is lacking. Since the publication of this review new data have been published on the validity of the CROM [69-71] and on the reproducibility of the inclinometer $[15,59,80]$. These studies generally have a high methodological quality and show good reproducibility of the inclinometer and good construct validity of the CROM.

The findings of this systematic review have implications for research and clinical practice. Researchers should give careful consideration to the study design and presentation of the results. The construct validity of a single inclinometer should be investigated by making comparisons with other instruments to measure ACROM. Future research should also report agreement parameters. Clinicians need to be cognizant that ACROM should be measured with the CROM or a single inclinometer and that visual estimation
Table 5 Summary of the quality assessment of clinimetric properties of the instruments included

+ Positive rating, - inadequate rating, ? doubtful rating, $\mathrm{O}$ insufficient information

\begin{tabular}{llllll}
\hline & Reliability & Agreement & Validity & Responsiveness & Interpretability \\
\hline CROM (ten studies) & + & $?$ & + & $\mathrm{O}$ & $\mathrm{O}$ \\
Universal goniometer (five studies) & $?$ & $?$ & $?$ & $?$ & $\mathrm{O}$ \\
Visual estimation (two studies) & - & $\mathrm{O}$ & $\mathrm{O}$ & $\mathrm{O}$ & $\mathrm{O}$ \\
Tape measure (four studies) & $?$ & $?$ & $?$ & $?$ & $\mathrm{O}$ \\
Single inclinometer (four studies) & + & + & $?$ & $\mathrm{O}$ & $\mathrm{O}$ \\
EDI-320 (two studies) & + & + & $\mathrm{O}$ & + & $\mathrm{O}$ \\
\hline
\end{tabular}


is not reliable. Furthermore, in future research different patient groups have to be studied, including for example also patients with cervical disc prostheses, in order to validate CROM against radiography.

\section{Conclusion}

The present review provides information for researchers and clinicians to facilitate choice amongst existing instruments for measuring ACROM. A systematic computerized literature search of databases revealed three different types of instruments that are practical to use when measuring ACROM in patients with non-specific neck pain: visual estimation, tape measurements, different types of goniometers/inclinometers. When a healthcare professional decides that measuring ACROM on a patient with nonspecific neck pain is necessary, a single inclinometer and CROM are to be recommended based on their best ratings for clinimetric properties and practicality. Visual estimation should not be used to measure ACROM.

Open Access This article is distributed under the terms of the Creative Commons Attribution Noncommercial License which permits any noncommercial use, distribution, and reproduction in any medium, provided the original author(s) and source are credited.

\section{References}

1. Agarwal S, Allison GT, Singer KP (2005a) Reliability of the spin-T cervical goniometer in measuring cervical range of motion in an asymptomatic Indian population. J Manipulative Physiol Ther 28(7):487-492

2. Agarwal S, Allison GT, Singer KP (2005b) Validation of the spin- $\mathrm{T}$ goniometer, a cervical range of motion device. J Manipulative Physiol Ther 28(8):604-609

3. Alantara H, Hurri H, Heliovaara M et al (1994) Flexibility of the spine: normative values of goniometric and tape measurements. Scan J Rehabil Med 14:147-154

4. Alund M, Larsson SE (1990) Three-dimensional analysis of neck motion; a clinical method. Spine 15:87-91

5. Amiri M, Jull G, Bullock-Saxton J (2003) Measuring range of active cervical rotation in a position of full head flexion using the 3D Fastrak measurement system: an intra-tester reliability study. Man Ther 8(3):176-179

6. Antonaci F, Bulgheroni M, Ghirmai S, Lanfranchi S, Dalla Toffola E, Sandrini G, Nappi G (2002) 3D kinematic analysis and clinical evaluation of neck movements in patients with whiplash injury. Cephalalgia 22(7):533-542

7. Assink N, Bergman GJ, Knoester B, Winters JC, Dijkstra PU, Postema K (2005) Interobserver reliability of neck-mobility measurement by means of the flock-of-birds electromagnetic tracking system. J Manipulative Physiol Ther 28(6):408-413

8. Balogun JA, Abereoje OK, Olaogun MO, Obajuluwa VA (1989) Inter and intratester reliability of measuring neck motions with tape measure and Myrin gravity-reference goniometer. J Orthop Sports Phys Ther 10:248-253

9. Bergman GJ, Knoester B, Assink N, Dijkstra PU, Winters JC (2005) Variation in the cervical range of motion over time measured by the "flock of birds" electromagnetic tracking system. Spine 30(6):650-654

10. Bogduk N (1984) Neck pain. Aust Fam Physician 13(1):26-30

11. Bot SD, Terwee CB, van der Windt DA, Bouter LM, Dekker J, de Vet HC (2004) Clinimetric evaluation of shoulder disability questionnaires: a systematic review of the literature. Ann Rheum Dis 63(4):335-341

12. Bot SD, van der Waal JM, Terwee $C B$, van der Windt DA, Schellevis FG, Bouter LM, Dekker J (2005) Incidence and prevalence of complaints of the neck and upper extremity in general practice. Ann Rheum Dis 64(1):118-123

13. Bruton A, Conway JH, Holgate ST (2000) Reliability: What is it, and how is it measured? Physiotherapy 86:94-99

14. Bulgheroni MV, Antonaci F, Ghirmai S, Sandrini G, Nappi G, Pedotti A (1998) A 3D kinematic method for evaluating voluntary movements of the cervical spine in humans. Funct Neurol 13(3):239-245

15. Bush KW, Collins N, Portman L, Tillet N (2000) Validity and intertester reliability of cervical range of motion using inclinometer measurements. J Man Manipulative Ther 8(2):52-61

16. Capuano-Pucci D, Rheault W, Aukai J, Bracke M, Day R, Patrick M (1991) Intratester and intertester reliability of cervical range of motion device. Arch Phys Med Rehabil 18:338-340

17. Chiu TT, Sing KL (2002) Evaluation of cervical range of motion and isometric neck muscle strength: reliability and validity. Clin Rehabil 16(8):851-858

18. Christensen HW, Nilsson N (1998a) Natural variation of cervical range of motion: a one-way repeated-measures design. J Manipulative Physiol Ther 21(6):383-387

19. Christensen HW, Nilsson N (1998b) The reliability of measuring active and passive cervical range of motion: an observer-blinded and randomized repeated-measures design. J Manipulative Physiol Ther 21(5):341-347

20. Cleland JA, Childs JD, Fritz JM, Whitman JM (2006) Interrater reliability of the history and physical examination in patients with mechanical neck pain. Arch Phys Med Rehabil 87(10):1388-1395

21. de Vet HC, Terwee CB, Knol DL, Bouter LM (2006) When to use agreement versus reliability measures. J Clin Epidemiol 59(10):1033-1039

22. Dvir Z, Gal-Eshel N, Shamir B, Prushansky T, Pevzner E, Peretz C (2006) Cervical motion in patients with chronic disorders of the cervical spine: a reproducibility study. Spine 31(13):E394-E399

23. Dvir Z, Prushansky T (2000) Reproducibility and instrument validity of a new ultrasonography-based system for measuring cervical spine kinematics. Clin Biomech (Bristol, Avon) 15(9):658-664

24. Dvorak J, Antinnes JA, Panjabi M, Loustalot D, Bonomo M (1992) Age and gender related normal motion of the cervical spine. Spine 17(10 Suppl):S393-S398

25. Dvorak J, Panjabi MM, Grob D, Novotny JE, Antinnes JA (1993) Clinical validation of functional flexion/extension radiographs of the cervical spine. Spine 18(1):120-127

26. Eechaute C, Vaes P, Van Aerschot L, Asman S, Duquet W (2007) The clinimetric qualities of patient-assessed instruments for measuring chronic ankle instability: a systematic review. BMC Musculoskelet Disord 8:6

27. Fejer R, Kyvik KO, Hartvigsen J (2006) The prevalence of neck pain in the world population: a systematic critical review of the literature. Eur Spine J 15(6):834-848

28. Ferrario VF, Sforza C, Serrao G, Grassi G, Mossi E (2002) Active range of motion of the head and cervical spine: a three-dimensional investigation in healthy young adults. J Orthop Res 20(1):122-129

29. Fitzpatrick R, Davey C, Buxton MJ, Jones DR (1998) Evaluating patient-based outcome measures for use in clinical trials. Health Technol Assess 2(14):i-iv (1-74) 
30. Frobin W, Leivseth G, Biggemann M, Brinckmann P (2002) Sagittal plane segmental motion of the cervical spine. A new precision measurement protocol and normal motion data of healthy adults. Clin Biomech (Bristol, Avon) 17(1):21-31

31. Haas M (1991) Statistical methodology for reliability studies. J Manipulative Physiol Ther 14(2):119-132

32. Haynes MJ, Edmondston S (2002) Accuracy and reliability of a new, protractor-based neck goniometer. J Manipulative Physiol Ther 25(9):579-586

33. Hole DE, Cook JM, Bolton JE (1995) Reliability and concurrent validity of two instruments for measuring cervical range of motion: effects of age and gender. Man Ther 1(1):36-42

34. Hoppenbrouwers M, Eckhardt MM, Verkerk K, Verhagen A (2006) Reproducibility of the measurement of active and passive cervical range of motion. J Manipulative Physiol Ther 29(5):363367

35. Hoving JL, Pool JJ, van Mameren H, Deville WJ, Assendelft WJ, de Vet HC, de Winter AF, Koes BW, Bouter LM (2005) Reproducibility of cervical range of motion in patients with neck pain. BMC Musculoskelet Disord 6:59

36. Hsieh CY, Yeung BW (1986) Active neck motion measurements with a tape measure. J Orthop Sports Phys Ther 8:88-92

37. Jenkinson TR, Mallorie PA, Whitelock HC, Kennedy LG, Garrett SL, Calin A (1994) Defining spinal mobility in ankylosing spondylitis (AS). The Bath AS Metrology Index. J Rheumatol 21(9):1694-1698

38. Jordan K (2000) Assessment of published reliability studies for cervical spine range-of-motion measurement tools. J Manipulative Physiol Ther 23(3):180-195

39. Jordan K, Dziedzic K, Jones PW, Ong BN, Dawes PT (2000) The reliability of the three-dimensional FASTRAK measurement system in measuring cervical spine and shoulder range of motion in healthy subjects. Rheumatology (Oxford) 39(4):382-388

40. Jordan K, Haywood KL, Dziedzic K (2004) Assessment of the 3dimensional Fastrak measurement system in measuring range of motion in ankylosing spondylitis. J Rheumatol 31(11):2207-2215

41. Kadir N, Grayson MF, Goldberg AA, Swain MC (1981) A new goniometer. Rheumatol Rehabil 20(4):219-226

42. Koerhuis CL, Winters JC, van der Helm FC, Hof AL (2003) Neck mobility measurement by means of the 'Flock of Birds' electromagnetic tracking system. Clin Biomech (Bristol, Avon) 18(1):14-18

43. Landis JR, Koch GG (1977) The measurement of observer agreement for categorical data. Biometrics 33(1):159-174

44. Lantz CA, Chen J, Buch D (1999) Clinical validity and stability of active and passive cervical range of motion with regard to total and unilateral uniplanar motion. Spine 24(11):1082-1089

45. Lantz CA, Klein G, Chen J, Mannion A, Solinger AB, Dvorak J (2003) A reassessment of normal cervical range of motion. Spine 28(12):1249-1257

46. Lohr KN, Aaronson NK, Alonso J, Burnam MA, Patrick DL, Perrin EB, Roberts JS (1996) Evaluating quality-of-life and health status instruments: development of scientific review criteria. Clin Ther 18(5):979-992

47. Love S, Gringmuth RH, Kazemi M, Cornacchia P, Schmolke M (1998) Interexaminer and intraexaminer reliability of cervical passive range of motion using the CROM and Cybex 320 EDI. J Can Chiropract Assoc 42(4):222-228

48. Maksymowich WP Mallon C, Richardson R, Conner-Spady B, Jauregui E, Chung C, Zappala L, Pile K, Russell AS (2006). Development and validation of a simple tape-based measurement tool for recording cervical rotation in patients with ankylosing spondylitis: comparison with a goniometer-based approach. J Rheumatol 33(11):2242-2249

49. Malmstrom EM, Karlberg M, Melander A, Magnusson M (2003) Zebris versus Myrin: a comparative study between a three- dimensional ultrasound movement analysis and an inclinometer/ compass method: intradevice reliability, concurrent validity, intertester comparison, intratester reliability, and intraindividual variability. Spine 28(21):E433-E440

50. Mannion AF, Klein GN, Dvorak J, Lanz C (2000) Range of global motion of the cervical spine: intraindividual reliability and the influence of measurement device. Eur Spine J 9(5):379-385

51. Moffett JAK, Hughes I, Griffiths P (1989) Measurement of cervical spine movements using a simple inclinometer. Physiotherapy 19:302-305

52. Morphett AL, Crawford CM, Lee D (2003) The use of electromagnetic tracking technology for measurement of passive cervical range of motion: a pilot study. J Manipulative Physiol Ther 26(3):152-159

53. O'Driscoll SL, Tomenson J (1982) The cervical spine. Clin Rheum Dis 8(3):617-630

54. Olson SL, O'Connor DP, Birmingham G, Broman P, Herrera L (2000) Tender point sensitivity, range of motion, and perceived disability in subjects with neck pain. J Orthop Sports Phys Ther 30(1):13-20

55. Ordway NR, Seymour R, Donelson RG, Hojnowski L, Lee E, Edwards WT (1997) Cervical sagittal range-of-motion analysis using three methods. Cervical range-of-motion device, 3space, and radiography. Spine 22(5):501-508

56. Pellechia GL, Bohannon RW (1998) Active lateral flexion range of motion measurements obtained with a modified goniometer, reliability and estimates of normal. J Manipulative Physiol Ther 21:443-447

57. Peollson A, Hedlund R, Ertzgaard S, Oberg B (2000) Intra- and intertester reliability and range of motion of the neck. Physiother Can 52(3):233-242

58. Petersen CM, Johnson RD, Schuit D (2000) Reliability of cervical range of motion using the OSI CA 6000 spine motion analyser on asymptomatic and symptomatic subjects. Man Ther $5(2): 82-88$

59. Piva SR, Erhard RE, Childs JD, Browder DA (2006) Inter-tester reliability of passive intervertebral and active movements of the cervical spine. Man Ther 11(4):321-330

60. Pringle RK (2003) Intra-instrument reliability of 4 goniometers. J Chiropract Med 3(2):91-95

61. Rheault W, Albright B, Byers C, Franta M, Johnson A, Skowronek M (1992) Intertester reliability of the cervical range of motion device. J Orthop Sports Phys Ther 15(3):147-150

62. Seffinger MA, Najm WI, Mishra SI, Adams A, Dickerson VM, Murphy LS, Reinsch S (2004) Reliability of spinal palpation for diagnosis of back and neck pain: a systematic review of the literature. Spine 29(19):E413-E425

63. Solinger AB, Chen J, Lantz CA (2000) Standardized initial head position in cervical range-of-motion assessment: reliability and error analysis. J Manipulative Physiol Ther 23(1):20-26

64. Stochkendahl MJ, Christensen HW, Hartvigsen J, Vach W, Haas M, Hestbaek L, Adams A, Bronfort G (2006) Manual examination of the spine: a systematic critical literature review of reproducibility. J Manipulative Physiol Ther 29(6):475-485 (485 e471-e410)

65. Strimpakos N, Sakellari V, Gioftsos G, Papathanasiou M, Brountzos E, Kelekis D, Kapreli E, Oldham J (2005) Cervical spine ROM measurements: optimizing the testing protocol by using a 3D ultrasound-based motion analysis system. Cephalalgia 25(12):1133-1145

66. Swinkels RA, Bouter LM, Oostendorp RA, van den Ende CH (2005) Impairment measures in rheumatic disorders for rehabilitation medicine and allied health care: a systematic review. Rheumatol Int 25(7):501-512

67. Terwee CB, Bot SD, de Boer MR, van der Windt DA, Knol DL, Dekker J, Bouter LM, de Vet HC (2007) Quality criteria were 
proposed for measurement properties of health status questionnaires. J Clin Epidemiol 60(1):34-42

68. Tousignant M, Boucher N, Bourbonnais J, Gravelle T, Quesnel M, Brosseau L (2001) Intratester and intertester reliability of the Cybex electronic digital inclinometer (EDI-320) for measurement of active neck flexion and extension in healthy subjects. Man Ther 6(4):235-241

69. Tousignant M, de Bellefeuille L, O'Donoughue S, Grahovac S (2000) Criterion validity of the cervical range of motion (CROM) goniometer for cervical flexion and extension. Spine 25(3):324330

70. Tousignant M, Duclos E, Lafleche S, Mayer A, TousignantLaflamme Y, Brosseau L, O'Sullivan JP (2002) Validity study for the cervical range of motion device used for lateral flexion in patients with neck pain. Spine 27(8):812-817

71. Tousignant M, Smeesters C, Breton AM, Breton E, Corriveau H (2006) Criterion validity study of the cervical range of motion (CROM) device for rotational range of motion on healthy adults. J Orthop Sports Phys Ther 36(4):242-248

72. Trott PH, Pearcy MJ, Ruston SA, Fulton I, Brien C (1996) Threedimensional analysis of active cervical motion: the effect of age and gender. Clin Biomech (Bristol, Avon) 11(4):201-206

73. Tucci SM, Hicks JE, Gross EG, Campbell W, Danoff J (1986) Cervical motion assessment: a new, simple and accurate method. Arch Phys Med Rehabil 67(4):225-230

74. Van Genderen FR, de Bie RA, Helders PJM, van Meeteren NLU (2003) Reliability research: towards a more clinically relevant approach. Phys Ther Rev 8:169-176

75. van Trijffel E, Anderegg Q, Bossuyt PM, Lucas C (2005) Interexaminer reliability of passive assessment of intervertebral motion in the cervical and lumbar spine: a systematic review. Man Ther 10(4):256-269

76. Veenhof C, Bijlsma JW, van den Ende CH, van Dijk GM, Pisters MF, Dekker J (2006) Psychometric evaluation of osteoarthritis questionnaires: a systematic review of the literature. Arthritis Rheum 55(3):480-492
77. Viikari-Juntura E (1987) Interexaminer reliability of observations in physical examinations of the neck. Phys Ther 67(10):15261532

78. Viitanen JV, Kokko ML, Heikkila S, Kautiainen H (1998) Neck mobility assessment in ankylosing spondylitis: a clinical study of nine measurements including new tape methods for cervical rotation and lateral flexion. Br J Rheumatol 37(4):377-381

79. Vos C, Verhagen A, Passchier J, Koes B (2007) Management of acute neck pain in general practice: a prospective study. Br J Gen Pract 57(534):23-28

80. Wainner RS, Fritz JM, Irrgang JJ, Boninger ML, Delitto A, Allison S (2003) Reliability and diagnostic accuracy of the clinical examination and patient self-report measures for cervical radiculopathy. Spine 28(1):52-62

81. Wang SF, Teng CC, Lin KH (2005) Measurement of cervical range of motion pattern during cyclic neck movement by an ultrasound-based motion system. Man Ther 10(1):68-72

82. Wolfenberger VA, Bui Q, Batenchuk GB (2002) A comparison of methods of evaluating cervical range of motion. J Manipulative Physiol Ther 25(3):154-160

83. Wu SK, Lan HH, Kuo LC, Tsai SW, Chen CL, Su FC (2007) The feasibility of a video-based motion analysis system in measuring the segmental movements between upper and lower cervical spine. Gait Posture 26(1):161-166

84. Youdas JW, Carey JR, Garrett TR (1991) Reliability of measurements of cervical spine range of motion-comparison of three methods. Phys Ther 71(2):98-104 (discussion 105-106)

85. Youdas JW, Garrett TR, Suman VJ, Bogard CL, Hallman HO, Carey JR (1992) Normal range of motion of the cervical spine: an initial goniometric study. Phys Ther 72(11):770-780

86. Zachman ZJ, Traina AD, Keating JC, Bolles ST, Braun-Porter L (1989) Interexaminer reliability and concurrent validity for the measurement of cervical ranges of motion. J Manipulative Physiol Ther 12:205-210 